\title{
REDES MEDIADORAS DE APOIO E PROTEÇÃO NA TRAJETÓRIA DE ADOLESCENTES VÍTIMAS DE BULLYING ESCOLAR E OS PROCESSOS DE RESILIÊNCIA EM-SI
}

\author{
Marcos Vinicius Francisco \\ Doutor em Educação pela Faculdade de Ciências e \\ Tecnologia da Universidade Estadual Paulista (FCT/UNESP). Docente do Programa de \\ Pós-Graduação em Educação da Universidade do Oeste Paulista (UNOESTE). \\ E-mail: marcos_educa01@yahoo.com.br

\section{Renata Maria Coimbra} \\ Doutora em Psicologia Escolar e Desenvolvimento Humano \\ pela Universidade de São Paulo (USP). Docente do Departamento de Educação e do \\ Programa de Pós-Graduação em Educação da Faculdade de Ciências e Tecnologia da \\ Universidade Estadual Paulista (FCT/UNESP). E-mail: coimbralibor@uol.com.br
}

\begin{abstract}
RESUMO
Neste artigo, analisou-se o impacto das redes mediadoras de apoio e proteção na trajetória de adolescentes vítimas de bullying escolar, favorecedoras da resiliência em-si. Como referencial foi utilizada a teoria histórico-cultural, que tem como base o materialismo histórico dialético. Os(as) participantes da pesquisa foram 06 jovens de uma escola pública, localizada no interior paulista. Como procedimentos metodológicos, adotaram-se entrevistas semiestruturadas com os participantes, para problematização do conteúdo implícito nas fotografias tiradas por eles e nas filmagens de um dia de suas vidas. Os resultados apontaram que, dentre as redes mediadoras de proteção, as relações interpessoais e familiares tiveram papel decisivo na vida dos(as) participantes, ao funcionarem como um ponto de apoio diante das adversidades vivenciadas, inclusive, as promotoras de bullying escolar. Muitas das práticas e atividades sociais experienciadas também funcionaram como mecanismos mediadores de proteção, pois permitiram que eles(as) se sentissem valorizados(as) e reconhecidos(as) pelo coletivo. No entanto, por mais que as redes pesquisadas, por meio dos processos de "resiliência em-si" tenham cumprido papel essencial ao auxiliá-los(as) no enfrentamento da condição em que se encontravam, não há como desconsiderar a continuidade do bullying escolar no sistema de organização capitalista.
\end{abstract}

PALAVRAS-CHAVE: bullying escolar; redes mediadoras de proteção; resiliência em-si; teoria histórico-cultural.

\section{MEDIATING SUPPORT AND PROTECTION NETWORKS IN THE TRAJECTORY OF VICTIMS OF SCHOOL BULLYING AND THE RESILIENCE IN ITSELF}

\begin{abstract}
In this study, it was analyzed the impact of mediating support and protection networks on the trajectory of adolescents victims of school bullying, favoring the resilience itself. As a reference, historical-cultural theory was used, based on dialectical historical materialism. The participants of the research were 06 young people from a public school, located in the interior of São Paulo state, Brazil. As methodological procedures, semi-structured interviews with the participants were adopted, to problematize the content implicit in the photographs taken by them and in the filming of a day of their lives. The results showed that, among the mediators of protection, interpersonal and family relations played a decisive role in the life of the participants, as they function as a point of support in the face of the adversities experienced, including the promoters of school bullying. Many of the practices and social activities experienced also functioned as mediating mechanisms of protection, since they allowed them to feel valued and recognized by the collective. However, even though the researched networks, through the processes of "resilience itself" played an essential role
\end{abstract}


in helping them to cope with the situation they were in, there is no way to disregard the continuity of school bullying in the system of capitalist organization.

KEYWORDS: school bullying; mediating protection networks; in-itself resilience; historicalcultural theory.

\section{REDES MEDIADORAS DE APOYO Y PROTECCIÓN EN LA TRAJETORÍA DE ADOLESCENTES VÍTIMAS DEL ACOSO ESCOLAR Y LOS PROCESOS DE RESILIENCIA EM SÍ}

\section{RESUMEN}

En este artículo, se analizó el impacto de las redes mediadoras de apoyo y protección en la trayectoria de adolescentes víctimas de acoso escolar, favorecedoras de la resiliencia en sí. Como referencial se utilizó la teoría histórico-cultural, que tiene como base el materialismo histórico dialéctico. Los participantes de la investigación fueron 06 jóvenes de una escuela pública, ubicada en el interior paulista, Brazil. Como procedimientos metodológicos, se adoptaron entrevistas semiestructuradas con los participantes, para problematización del contenido implícito en las fotografías tomadas por ellos y en el rodaje de un día de sus vidas. Los resultados apuntaron que, entre las redes mediadoras de protección, las relaciones interpersonales y familiares tuvieron un papel decisivo en la vida de los(as) participantes, al funcionar como un punto de apoyo ante las adversidades vivenciadas, inclusive, las promotoras de acoso escolar. Muchas de las prácticas y actividades sociales experimentadas también funcionaron como mecanismos mediadores de protección, pues permitieron que ellos(as) se sintieran valorizados(as) y reconocidos(as) por el colectivo. Sin embargo, por más que las redes investigadas, por medio de los procesos de "resiliencia en sí" hayan cumplido papel esencial al auxiliarlos(las) en el enfrentamiento de la condición en que se encontraban, no hay como desconsiderar la continuidad del bullying escolar en el sistema de organización capitalista.

PALABRAS CLAVE: acoso escolar; redes mediadoras de protección; resiliencia en sí; la teoría histórico-cultural.

\section{INTRODUÇÃO}

Neste artigo $^{1}$, defende-se a tese de que a personalidade de cada indivíduo se constrói a partir do contato com a realidade objetiva, incorporadas ou não as possibilidades para uma atividade consciente. Quanto menores forem essas possibilidades, mais fragmentados serão os motivos e ações presentes na atividade humana. Decorrente disso, no sistema de organização capitalista, ao analisar o bullying escolar, evidencia-se uma contradição, pois mesmo que estudantes, vítimas de bullying, recebam apoio das redes mediadoras de proteção, presentes nas esferas da sociabilidade humana e se posicionem diante dessa manifestação de violência, por meio dos processos de "resiliência em-si", o enfrentamento será pontual. Os(as) estudantes continuarão adaptados(as) ao modelo de organização social que produz o bullying escolar.

O bullying escolar não deve ser entendido como fruto da relação imediata entre agressores e vítimas, haja vista que ele é um produto das relações capitalistas de produção;

\footnotetext{
${ }^{1}$ Este artigo é um recorte de tese doutoral em Educação que contou com financiamento da Fundação de Amparo à Pesquisa do Estado de São Paulo (FAPESP).
} 
expresso nas manifestações de perseguição e intimidação daqueles(as) que não se ajustam aos padrões culturais de corpo, modos de ser e agir criados e difundidos pela burguesia, a serviço da manutenção das relações sociais (FRANCISCO; COIMBRA, 2015).

Entende-se por "resiliência em-si", o processo de enfrentamento das adversidades vivenciadas por um indivíduo, mas que não oportuniza, ainda, o estabelecimento de relações conscientes com as formas que produzem sua vida, o que impede o pleno desenvolvimento da personalidade humana. A "resiliência em-si" está abaixo da emancipação e deverá ser superada por incorporação. A emancipação, por sua vez, não é um processo individual, mas um produto da superação das relações entre dominados e dominantes.

Nessa perspectiva, Leontiev (1978) pontua que a dimensão humana presente no homem advém de sua inserção social, por meio do contato com as produções e significações de uma dada cultura. Leontiev (1978, 1983, 1989) e Martins (2001, 2004, 2011) salientam ser impossível estudar a formação da personalidade humana, caso não se considere sua construção a partir das interações sociais objetivas presentes na vida de cada indivíduo. As condições objetivas de vida são relações e atividades sociais, apropriações culturais que engendram a construção dos pensamentos, sentimentos, consciência e da própria personalidade (LEONTIEV, 1983, 1989).

Leontiev (1983) assevera que, na análise do conceito de personalidade é imprescindível compreender alguns elementos do surgimento da consciência no homem. Os seres humanos, ao desenvolverem sua produção e comunicação material, transformaram a natureza, o seu pensamento e a consciência. A consciência, nesse prisma, é entendida como um produto social, sendo que as transformações nela sofridas são impactadas pelas condições de desenvolvimento da divisão social do trabalho. A expropriação econômica gerada pela iniciativa privada conduz a alienação, ou seja, a desintegração da consciência das pessoas (MARTINS, 2011).

Destarte, neste artigo, objetivou-se analisar o impacto das redes mediadoras de apoio e proteção na trajetória de adolescentes vítimas de bullying escolar, favorecedoras da resiliência em-si.

\section{O bullying escolar e a "resiliência em-si": uma interpretação histórico-cultural}

Dentre as diversas formas de violência que ocorrem no ambiente escolar, vem ganhando ênfase nos últimos anos o bullying escolar. Olweus (2006) salienta que o termo 
tem sido empregado para classificar situações nas quais um estudante é perseguido ou intimidado de maneira individual ou grupal nos espaços escolares. Destaca, ainda, o caráter intencional, repetitivo e assimétrico nas ameaças e perseguições.

Francisco e Coimbra (2015) apontam que a conceituação proposta por Olweus se mostra insuficiente, ao não superar as questões mais individualistas e ao não enfatizar a influência dos aspectos histórico-culturais. Há que se garantir a compreensão do bullying como uma manifestação humana, socialmente construída.

No que tange aos papéis dos(as) estudantes nas situações de bullying escolar, Avilés (2010), Bandeira (2009) e Zequinão et al. (2016) apontam os(as) autores(as)/agressores(as), os(as) alvos (vítimas típicas ou agressoras) e os(as) espectadores(as)/testemunhas. As consequências do bullying escolar afetam todos os envolvidos em sua dinâmica. No caso, em específico, das vítimas, foco deste artigo, Lisboa, Braga e Ebert (2009) e Bottel e Bermúdez (2017) ponderam para o fato de que o bullying escolar pode ter efeitos a curto, médio e longo prazo, ao influenciar as atitudes, os comportamentos, o autoconceito das vítimas, a imagem dos outros, do mundo e até da própria vida.

A inserção dos indivíduos nas ocorrências de bullying escolar refletem as relações sociais que fomentam a linguagem da violência, como um meio de excluir ou de se impor perante os outros (FRANCISCO; COIMBRA, 2015; BOTTEL; BERMÚDEZ, 2017). Muitas crianças e adolescentes assumem determinadas atitudes, como um meio de se firmar perante os pares (FRANCISCO; COIMBRA, 2015; LISBOA; BRAGA; EBERT, 2009). "Reforçar e não denunciar comportamentos agressivos de algumas crianças para com outras pode aumentar a popularidade individual - tão almejada em grupos de pares na infância e adolescência" (LISBOA; BRAGA; EBERT, 2009, p.63).

Nesta pesquisa, participaram estudantes que experienciaram o bullying escolar no papel de vítimas, todavia eles haviam se posicionado sobre tal manifestação de violência, por meio dos processos de "resiliência em-si".

Edwards e Apostolov (2007), por meio da teoria histórico-cultural, compreendem o conceito de resiliência a partir do momento no qual os indivíduos em condição de vulnerabilidade social são capazes de intervir e remodelar as condições sociais de seu desenvolvimento. Os avanços na interpretação de Edwards e Apostolov (2007) são inegáveis, porém, uma das contradições expressas no sistema de organização capitalista refere-se ao fato de que, embora muitos indivíduos se posicionem ou enfrentem as 
adversidades vivenciadas, eles estarão centrados, apenas, nos processos da "resiliência emsi”. A resiliência em-si é o reflexo imediato da adaptabilidade ao contexto social.

O termo "em-si”" utilizado para designar a "resiliência em-si", advém das produções de Duarte (1999, 2007), ao explicitar as diferenças presentes nas objetivações genéricas (em-si e para-si), que por sua vez não têm existência independente da história. A estrutura das objetivações genéricas, em níveis, reflete o grau de humanização alcançado pelo gênero humano. A partir de Agnes Heller, o autor esclarece que ambas são categorias tendenciais e relativas.

[...] São relativas porque tanto podem ser utilizadas tomando-se por referência a relação entre homem e natureza, caso em que o ser-em-si será a natureza e o ser-para-si a sociedade; quanto podem ser utilizadas considerando-se apenas o âmbito da prática social humana, na qual o serem-si caracteriza a genericidade que se efetiva sem que haja uma relação consciente dos homens para com ela e o ser-para-si caracteriza a ascensão dessa genericidade ao nível da relação consciente (DUARTE, 1999, p.135).

Conforme Duarte (1999), todos os indivíduos ingressam no gênero humano por meio de um processo formativo em-si. Isso não significa que a apropriação das objetivações genéricas em-si ocorra de forma similar para todos, independentemente do tempo histórico e da posição ocupada por cada um no interior das relações sociais. Ninguém vive em sociedade, sem realizar um mínimo que seja de apropriações dessas objetivações. Quanto menos alienada a sociedade, mais estarão presentes as objetivações genéricas para-si.

\section{Método}

A presente investigação, por meio da teoria histórico-cultural, que tem como base epistemológica o método do materialismo histórico dialético, busca apreender a realidade investigada (MARX; ENGELS, 1974). De acordo com Vigotski (1995), nessa perspectiva: a) devem-se explicar os fenômenos em oposição à descrição; b) é necessário explicitar a análise dos nexos dinâmico-causais, a fim de compreender a origem do fenômeno, na busca pela síntese de suas múltiplas determinações; c) os processos devem ser analisados dialeticamente desde suas formas mais simples para as formas mais complexas e vice versa.

Neste artigo, será dada atenção especial às redes mediadoras de apoio e proteção (relações interpessoais, familiares, diferentes segmentos sociais, tais como a educação 
escolar e práticas e atividades sociais que os(as) mesmos(as) participam) que serviram como um ponto de apoio ou referências institucionais sociais na vida dos(as) participantes.

\section{Local de pesquisa e processo de seleção inicial dos(as) participantes}

A pesquisa foi desenvolvida em uma escola que atende estudantes de Ensino Fundamental e Médio, em uma cidade de médio porte do interior de São Paulo. A seleção se deu por meio de um sorteio aleatório dentre as escolas da cidade, que atendiam aos segmentos mencionados. Com a autorização concedida, iniciou-se o contato com todas as turmas de $9^{\circ}$ anos do Ensino Fundamental (07 turmas) e $1^{\circ}$ anos do Ensino Médio (06 turmas) para apresentar a pesquisa, entregar e recolher os Termos de Consentimento Livre Esclarecido (TCLE) dos(as) estudantes interessados(as) em participar e que tinham autorização dos(as) responsáveis. Tal atividade durou duas semanas e ao final recolheramse 36 TCLE.

A escolha por tal faixa etária deu-se pelo fato dos estudos sobre bullying escolar indicarem que são nessas idades que costumam haver as maiores incidências do fenômeno (OLWEUS, 2006). A opção por tais séries ofereceu a oportunidade de ter como participantes, estudantes com longos anos de inserção escolar e com possibilidades de terem sofrido o bullying escolar.

Os(as) 36 estudantes foram convidados(as) a responderem o questionário ScanBullying elaborado por Almeida e Caurcel (2005). O Scan-Bullying é composto de uma prancha que ilustra uma história com dez situações de perseguição a um(a) estudante, e que serviu para que eles refletissem acerca das questões propostas no questionário. Em momento posterior, procedeu-se pela tabulação dos dados, com o auxílio do software SPSS versão 12.0, que permitiu a identificação dos(as) estudantes expostos(as) ao bullying escolar, que foram os(as) participantes da etapa seguinte (14 estudantes).

Os(as) estudantes que vivenciaram o bullying escolar foram contatados(as) para aplicação de outros dois instrumentos de pesquisa: o questionário CYRM (Child and Youth Resilience Measure), que mensurou processos de resiliência e o questionário "Fatores de Risco e Proteção em adolescentes de Presidente Prudente", que possibilitou a identificação de outros mecanismos mediadores de riscos presentes em suas vidas, além do bullying escolar. Dos(as) 14 estudantes selecionados(as), apenas 12 participaram, sendo que duas jovens haviam transferido de escola. O CYRM foi criado a partir de pesquisas com adolescentes de 14 comunidades de cinco continentes (UNGAR et al., 2005; UNGAR et 
al., 2007), tendo sido validado por Ungar e Liebenberg (2008) como medida de resiliência, culturalmente significativa. O questionário "Fatores de risco e proteção em adolescentes de Presidente Prudente" foi elaborado pela segunda autora da pesquisa e validado em $2008^{2}$.

A partir de análises dos resultados dos instrumentos apresentados acima, foram selecionados(as) 06 estudantes que apresentaram, concomitantemente, níveis significativos de resiliência e mecanismos mediadores de risco em suas trajetórias de vida.

Ao entender o bullying escolar e a resiliência como condições postas pelas circunstâncias atuais, é possível se ter instrumentos como os utilizados, a fim de se identificar os(as) envolvidos(as) em situações de bullying, bem como os recursos e as formas de enfrentamentos por eles(as) utilizados(as). Contudo, esses instrumentos por si só, não dariam conta de identificar a essência do objeto da pesquisa, ainda mais no referencial adotado. Até mesmo porque se deve ir para além da aparência do fenômeno. Daí a importância de outros procedimentos, os quais serão apresentados posteriormente, a fim de contemplar aspectos da dinâmica organizacional/estrutural da sociedade burguesa e que se refletem no objeto investigado. Conforme Paulo Netto (2011), a partir das proposições da teoria marxiana:

[...] os instrumentos e também as técnicas de pesquisa são os mais variados, desde a análise documental até as formas mais diversas possível de observação, recolha dos dados, quantificação etc. Esses instrumentos e técnicas são os meios de que se vale o pesquisador para "apoderar-se da matéria", mas não devem ser identificados com o método: instrumentos e técnicas similares podem servir (e de fato servem) em escala variada, a concepções metodológicas diferentes (PAULO NETTO, 2011, p.26).

Tais ponderações se aplicam a todos os instrumentos utilizados no processo de identificação dos(as) participantes da pesquisa. É válido reforçar, mais uma vez, que o seu uso deu-se, apenas, com o intuito de selecionar os(as) estudantes com os quais seriam realizadas entrevistas semiestruturadas, a partir de fotografias e filmagens de seu cotidiano, com posterior edição de clipes.

\section{Participantes da pesquisa}

Os(as) 06 estudantes selecionados(as) (04 moças e 02 rapazes) para a fase de entrevistas, fotografias e filmagens residiam em diferentes bairros do município. Apenas Elenita residia no bairro onde a escola estava localizada; Achilles, Irineu e Renata

\footnotetext{
${ }^{2}$ Bolsa FAPESP, Capacitação Técnica Nível I em 2006 e Nível III em 2007.
} 
Revista do Programa de Pós- Graduação em Educação da UFPI | ISSN 2526-8449 (Eletrônico) 1518-0743 (Impresso)

moravam em bairros próximos ao da escola, enquanto que Andréia e Rosiane deslocavamse de bairros distantes da cidade.

\section{Fotografias e filmagens}

O processo de captação das imagens e de filmagens seguiu o desenho metodológico criado por Ungar (2008). Antes do período de captação de imagens por meio das fotografias e filmagens, realizaram-se com os(as) seis participantes, uma entrevista inicial, com média de trinta minutos cada, sendo que elas foram gravadas, seguindo um roteiro de perguntas que possibilitou a compreensão de alguns dos mecanismos mediadores de risco e proteção nos contextos familiares, escolares e comunitários, associados aos processos de "resiliência em-si", bem como provocá-los(as) para a coleta de imagens. O roteiro de entrevistas foi elaborado a partir de Libório (2011) e Ungar et al., (2007), sendo que algumas questões foram incluídas, por serem essenciais na perspectiva do método materialista histórico dialético, a fim de analisar o bullying escolar e a "resiliência em-si" frente aos determinantes sociais.

$\mathrm{Na}$ entrevista inicial abordou-se: o que achavam da escola onde estudavam (estrutura, funcionamento, colegas, funcionários(as)); sobre a presença de conflitos (tipos, opinião sobre os mesmos); o que pensavam sobre o papel do governo frente ao funcionamento da escola; espaços existentes ou não para os(as) estudantes mobilizarem-se coletivamente frente as suas necessidades; participação dos(as) estudantes nesses espaços e como funcionavam; o que faziam diante das dificuldades em suas vidas, exemplos de situações/desafios e onde buscavam forças (apoio); como os relacionamentos na vida dos(as) adolescentes eram importantes (adequou-se as pessoas que eles(as) apontavam) e o que significavam; o que achavam que as pessoas mais velhas pensavam dos(as) mais jovens e se respeitavam suas opiniões; como são eram seus(suas) amigos(as), o que os(as) amigos(as) gostavam de fazer e por que os(as) entrevistados(as) gostavam desses amigos.

Ao final dessas entrevistas, conversou-se com os(as) adolescentes sobre a captação de imagens, pois ao usarem as câmeras fotográficas digitais deveriam tirar fotos dos elementos (pessoas, lugares, espaços, objetos) que consideravam positivos ou negativos em suas trajetórias de vida. De posse de câmeras digitais, realizou-se à entrega das mesmas para os(as) jovens tirarem 28 fotografias, num total de 21 dias.

Após a revelação das fotografias, os(as) adolescentes passaram por outra entrevista sobre o conteúdo das fotos tiradas e que duraram em média 20 minutos cada. Esse roteiro 
de entrevista foi baseado a partir de Libório (2011) e Ungar et al., (2007): - As fotografias que mostravam aquilo que os(as) faziam apreciar morar na sua comunidade, bem como o inverso e as explicações para tal; - Os significados das demais fotografias e se gostariam de conversar sobre algo não abordado, até então.

Em um terceiro momento, realizou-se uma filmagem de um dia de suas vidas " $a$ Day in the life" Gillen et al., (2006), na qual os(as) participantes foram filmados(as) nas atividades cotidianas ( 8 horas de filmagens de cada), sendo que utilizou-se dois dias de filmagens para cada jovem. Nas filmagens, uma auxiliar de pesquisa fez anotações no diário de campo.

Após as filmagens, iniciou-se o processo de assistir as aproximadamente 48 horas de gravações. Posteriormente, editou-se na forma de um DVD com 5 a 6 clipes, as filmagens de cada participante, compondo um vídeo de aproximadamente 30 minutos. Na edição, utilizou-se o software Pinnacle, versão 11.0. Após esta tarefa os(as) jovens foram convidados(as), individualmente, a assistirem aos vídeos sobre suas respectivas filmagens e realizou-se uma última entrevista. Diante das práticas/atividades socioculturais em diferentes espaços que apareceram nas filmagens, analisou-se com os mesmos uma a uma e foram feitos alguns questionamentos, a fim de buscar mais subsídios para a análise do material. Cada entrevista durou aproximadamente 2 horas, sendo que foram problematizados os seguintes elementos:

- Esclarecer o que se via nos clipes (perspectiva dos adolescentes); os trechos que mostravam que eles(as) gostavam de morar em sua comunidade, bem como o inverso e suas explicações; analisar se os trechos selecionados contemplaram suas forças pessoais e redes mediadoras de apoio social (quando tiveram dificuldades ou buscaram ajuda) e se havia algum evento filmado que deveria fazer parte do clipe, bem como suas justificativas.

Frente a tais apontamentos, dialeticamente, na análise dos dados foram apresentados os seguintes eixos analíticos: A importância das redes mediadoras de apoio e proteção frente ao processo de formação da personalidade humana; A escola como um local de apoio e proteção.

Tal configuração visa apresentar a importância que as redes mediadoras de apoio e proteção tinham na vida dos(as) participantes da pesquisa. Entende-se que tais redes serviam como um "ponto de apoio" ou referências institucionais sociais. Elas contribuíram no fortalecimento da autoestima, bem como na construção da personalidade daqueles(as) 
que foram expostos(as) a situações de bullying escolar e que conseguiram se posicionar frente às mesmas, conquanto, apenas no âmbito da "resiliência em-si".

\section{Análise dos dados}

Inicia-se este tópico apresentando os 06 participantes, a partir dos "motivos" que os(as) levaram a serem identificadas como vítimas do bullying escolar, a fim de garantir uma visão mais integrada do todo, frente aos eixos analíticos.

Andréia - ao falar sobre os grupos tratados injustamente na sociedade, vítimas de preconceito, destacou os evangélicos. A perseguição constante que sofria estava ligada a não realização de atividades desempenhadas por outros(as) jovens, tais como, frequentar festas e ouvir músicas para além do estilo gospel. O bullying escolar em seu caso estava relacionado à sua religiosidade. Com poucas amizades na escola, procurava superar a timidez, por meio da participação nas atividades religiosas e diante do contato com os(as) amigos(as) desse espaço.

Elenita - apresentou nas diferentes etapas da pesquisa o discurso de uma vítima de bullying escolar, em função de sua estrutura física (sobrepeso). Ao conversar sobre as fotografias, apresentou uma foto de sua sala de aula vazia, como a que menos gostou, ao justificar que lá aconteciam os xingamentos. Indagada, se havia tirado alguma foto capaz de representar algo difícil que tenha passado em sua vida, relatou que se pudesse tirar, ilustraria os "falatórios" que envolviam a sua pessoa e lhe faziam mal.

Achilles - na primeira entrevista pontuou haver situações de bullying na escola, principalmente por meio de perseguições, em função dos aspectos físicos das pessoas. Contudo, disse que tentava entrar na brincadeira como se fosse normal. Durante as fases da pesquisa, em especial, nos momentos das filmagens percebeu-se preocupação excessiva com os aspectos físicos, ao ressaltar a importância das pessoas cuidarem de sua aparência. Em função disso, frequentava uma academia privada de musculação, ao alegar à necessidade de ganhar massa corporal, pois se considerava muito magro. Infere-se que o possível bullying que Achilles sofria advinha das questões físicas de seu corpo.

Renata - apontou não haver muitos conflitos e perseguições entre os(as) estudantes de sua escola, embora fosse perseguida, constantemente, pelos(as) companheiros(as), desde quando passou a estudar naquela escola $\left(6^{\circ}\right.$ ano). No conjunto das fases da pesquisa, percebeu-se que as perseguições decorriam do fato dela não se adequar financeiramente ao 
grupo de colegas. Ela não possuía nenhuma amizade, para além das que viviam em seu bairro, este, localizado em uma área de alta exclusão social.

Rosiane - disse que gostava da maioria dos(as) colegas de escola, embora, de alguns(algumas) não, tendo em vista que eles(elas) zombavam de sua magreza. Com um discurso de naturalização, mencionou haver conflitos e brigas entre os(as) estudantes, o que considerava normal. Por mais que fosse vítima de bullying, em função de sua magreza, relatou que não se importava com isso.

Irineu - Embora não tenha ficado explícito, as práticas religiosas e o excelente desempenho escolar eram os possíveis motivos do bullying escolar sofrido. Por apresentar muita dificuldade em construir amizades com os(as) colegas de escola, aliado a sua timidez, mencionou que os(as) colegas de escola não tinham os mesmos interesses que o seu, por isso não havia o que dialogar com eles. Suas amizades foram construídas com pessoas mais velhas e que frequentavam sua igreja, espaço no qual se sentia bem, pois expressava o seu gosto pela música e obtinha reconhecimento. Destaca-se que seus(suas) professores(as) e funcionários(as) da escola admiravam sua organização e empenho nas atividades escolares.

\section{A importância das redes mediadoras de apoio e proteção frente ao processo de formação da personalidade humana}

Ao destacar a importância que as redes mediadoras de apoio e proteção (relações interpessoais, familiares ou de diferentes segmentos sociais) tinham na vida dos(as) participantes da pesquisa, há que se destacar que muitas das práticas e atividades sociais que os(as) mesmos(as) participavam, também funcionavam como mecanismos mediadores de proteção em suas vidas, ao passo que eles sentiam-se valorizados(as) e reconhecidos(as) perante o coletivo. Todavia, deve-se esclarecer que as mesmas serão apresentadas, na forma de categorias, apenas, para facilitar a compreensão do(a) leitor(a), embora se deva entendê-las como parte de um todo indivisível, num movimento dialético.

Num primeiro momento, destaca-se a importância que os familiares e as amizades demarcam como importantes redes mediadoras de apoio e proteção. E, por último, mas não menos importante, destaca-se o papel que a escola pode desempenhar em seu processo de formação, por meio do desenvolvimento de suas funções psicológicas superiores, atreladas à formação de personalidades com consciência social e política. Consequentemente almeja-se que ela prepare os indivíduos para superar os antagonismos gerados a partir das 
relações sociais presentes no capitalismo, na luta por outra estrutura social, onde prevaleça à unidade entre atividade e motivos vitais.

De acordo com Martins (2011), "a desarticulação entre atividades e motivos, ou a inexistência desta unidade na personalidade, cria as condições internas para que o homem viva fragmentariamente, em consonância com motivos-estímulos em detrimento dos motivos vitais". Posto isso, somente num outro plano de relações sociais, o bullying escolar será superado e incorporado, para além de seu enfrentamento pontual.

Defende-se que as redes mediadoras de apoio e proteção se constituem e ganham sentido, apenas, se entendidas como pertencentes ao gênero humano. É na interação social com o outro que um indivíduo constrói sua personalidade e, por conseguinte, se apropria e objetiva as produções históricas.

Conforme Martins (2011), no processo de formação da personalidade, um dos princípios fundamentais diz respeito aos vínculos do indivíduo com o mundo. Tais vínculos contemplam suas relações com as condições objetivas de vida e ocorrem em dada família, classe social, nação, contexto histórico etc. Os vínculos favorecem o contato do indivíduo com um amplo conjunto de atividades, por meio das quais são construídas as estruturas motivacionais e emocionais, essenciais na formação da personalidade.

A análise da qualidade desses vínculos não pode levar em consideração apenas a dimensão quantitativa; em que medida é amplo ou não o mundo que se descortina para o indivíduo; deve considerar, acima de tudo, o conteúdo das relações objetivas e sociais que esses vínculos representam, uma vez que esses conteúdos são condicionados pelo patrimônio de apropriações que se disponibilizaram para a pessoa (MARTINS, 2011, p.121).

Apresenta-se, abaixo, uma descrição com posterior explicação das redes mediadoras de apoio e proteção presentes na vida dos(as) participantes.

Elenita destacou os(as) amigos(as) e a mãe como redes de proteção em sua vida. De acordo com a jovem são as pessoas a quem podia recorrer e que a aconselhavam diante de qualquer dificuldade. Por conseguinte, por intermédios dos familiares em sua casa e dos(as) amigos(as) na escola, ela buscava força e apoio. Ao apresentar a foto que mais gostou e a que representava algo bom em sua vida, a participante fez referência a uma com o grupo de amigos(as), e disse que a mesma simbolizava a amizade que possuía nas horas mais difíceis. Dificuldades essas que perpassavam também os conteúdos da esfera escolar. 
Durante as filmagens, ao interagir com uma amiga e sua mãe, Elenita ressaltou sobre a importância das amizades, diante dos momentos que as pessoas precisam de alguém para desabafar ou dialogar, e que, as pessoas que não têm amizades devem se sentir muito mal. Embora tivesse uma ótima relação com a mãe, acreditava que as amizades com os pares são mais confiáveis, tendo em vista que eles a compreendiam melhor. Como exemplo, da interação com os(as) amigos(as), mencionou uma atividade não filmada e que fazia parte de sua vida, ou seja, os momentos de interação com os amigos na Lagoa dos Patos (Parque do Bairro).

Ao referir sobre a importância que as amizades podem ter na vida de um indivíduo, entende-se que elas são extensões do processo de humanização do gênero humano. Humanização que não perpassa somente o contato com o outro, mas que culmina também nas possibilidades de apropriação dos produtos historicamente construídos, por meio das práticas sociais e culturais e que favorecem o desenvolvimento da personalidade de uma dada pessoa.

Gandra, Viotto Filho e Ponce (2012) enfatizam a importância do outro no processo de desenvolvimento humano-genérico. Os fatores biológicos são parte do processo, mas sozinhos não garantem a humanização. Vigotski (2001) criticava autores que secundarizavam a importância das dimensões sociais no processo de desenvolvimento de uma criança, como se o biológico fosse inerente à mesma, ao considerá-lo como o elo principal e determinante. Assim, Vigotski propôs que, a criança deve ser entendida como um sujeito de relações sociais, tendo em vista que a sua participação na vida social se efetiva desde o seu nascimento.

O participante Irineu disse não ter muitas amizades e que não conversava com os(as) colegas de sua idade na escola, embora os(as) considerassem afetivos(as) com as pessoas ao seu redor. Inclusive, mencionou que, por mais que conversasse com os(as) colegas de classe, não conseguia ter uma maior proximidade e alegou não realizar as mesmas atividades e se interessar pelas conversas deles(as). Disse ser um garoto fechado e tímido e justificou que o motivo decorria do seu jeito e personalidade. As amizades conquistadas sempre são com pessoas mais velhas e que faziam parte da sua igreja. Ele deixou claro que sabia da necessidade das pessoas terem amizades, contudo, apresentava problemas de relacionamentos mais profícuos com seus pares na escola. Diante das dificuldades, além da busca pelo apoio religioso, disse ter na família o apoio necessário. 
Ele pontuou ter uma ótima relação com os pais, ao tê-los sempre para dialogar e tirar suas dúvidas.

Sobre a participante Andréia, é importante destacar que ela vivia em constantes mudanças de endereço, sendo que em alguns momentos residia com a mãe e em outros com o pai, na tentativa de sempre agradá-los, pois eles eram divorciados, desde criança. Seus pais já tentaram a reconciliação algumas vezes. Andréia disse que era muito apegada aos familiares, sendo que ao apresentar a foto que lhe remetia a algo ruim em sua vida, destacou uma tirada da rua de sua casa, na tentativa de simbolizar a distância que a separava de uma de suas irmãs que se mudou de cidade. Ela era muito apegada a essa irmã e a considerava como um exemplo em sua vida, pela maneira de encarar e enfrentar os problemas, sendo que, muitas vezes, pensava em fazer os outros, ao seu redor, mais felizes do que a si mesma. Ainda apresentou uma foto da casa da mãe, onde vivia durante a fase das captações de imagens, a fim de ilustrar o melhor lugar de se viver (casa dos pais), pois é lá que recebia conselhos e cuidados quando precisava.

Ela ressaltou ter poucas amizades, disse ser bem seleta, considerava as que tinha muito importantes, pois quando estava desanimada, inclusive, chorava com eles(as). A participante mencionou, ainda, ter os(as) amigos(as) como sua família e espelho. Posteriormente, destacou que a maioria das amizades relacionava-se à religião. Por ser tímida tinha dificuldades de se socializar na escola, onde possuía apenas uma amiga.

No que tange à figura de Achilles, ele apontou que diante de qualquer dificuldade, sempre contava primeiro com a ajuda da família, na figura da mãe e do pai. O participante mencionou que sua família era seu "tudo", e pensava muito que um dia poderá não tê-los ao seu lado. Durante a entrevista sobre as fotografias, ficou indignado e não se conformava de não ter tirado fotos da família reunida.

Assim como os(as) demais participantes, Achilles tinha poucos(as) amigos(as), sendo que considerava a maioria das pessoas com as quais se relaciona socialmente, apenas, como colegas, e creditou as amizades um papel importante durante as atividades sociais (jogos, festas e brincar). Destacou que a amizade com outras pessoas era importante, para ter sempre alguém com quem contar/ajudar e vice versa. Disse, ainda, que viver sem amizades seria complicado, sendo que jamais conseguiria viver em tal condição. Como exemplo de amizades, apresentou uma série de fotos em momentos junto aos(as) seus(suas) amigos(as). 
Merece ser problematizado, o fato de ele responsabilizar as pessoas que não possuíam amizades, como se elas fossem responsáveis por tal. Sendo assim, classificava as pessoas que se encontravam em tal situação como sujeitos que não se ajustavam aos grupos sociais e disse não se sensibilizar com a situação delas. Ao contestá-lo se não seria um direito de uma pessoa ter hábitos e costumes, bem como pensar diferente de um determinado grupo, o mesmo argumentou que:

Então ela não vai ficar com a gente, porque se ela pensa diferente, os grupos sociais são formados por causa disso, pessoas que pensam o contrário, elas mesmas não vão querer ficar por perto (ACHILLES, PARTICIPANTE DA PESQUISA DE CAMPO).

Nos trechos evidencia-se uma visão individualista por parte do participante, ao passo que ele não leva em consideração a diversidade cultural, como se as pessoas tivessem que se enquadrar dentro de todos os grupos sociais, sem que suas individualidades e particularidades sejam respeitadas. Isso é um agravante que merece ser problematizado, pois são situações como essa que geram o racismo, a homofobia ou até mesmo o bullying escolar.

O movimento de produção deste artigo buscou respostas para tais situações, ao entendê-las como decorrentes do senso comum, ou seja, como constatação da realidade. Posto isso, defende-se um trabalho educativo que possibilite aos(as) estudantes da escola pública o desenvolvimento da consciência crítica, a fim de que possam compreender o porquê das práticas assentadas no individualismo, por exemplo, estarem a serviço da manutenção das relações sociais. Apregoa-se que o individualismo seja apenas mais um impeditivo para a tomada do processo de consciência que faz com que as pessoas continuem centradas nas relações neoliberais, estabelecidas pelo modo capitalista de produção.

Sobre o individualismo na sociedade capitalista, Heller (1977) afirma que devido a inúmeras exigências dos grupos inerentes à sociedade, nas quais os indivíduos assumem vários papéis em decorrência da divisão social do trabalho, com a agravante falta de instâncias mediadoras que os constituam como comunidade no seio da sociedade, os indivíduos perdem sua totalidade unitária, fragmentam-se e reproduzem essa fragmentação. Para a autora, a carência de comunidade converte-se, em princípio, para o surgimento do individualismo na sociedade, tendo em vista que no capitalismo defende-se que o homem nasce livre e sua existência individual acontece de forma independente de 
sua existência social. Os indivíduos convertem, explicitamente, seus interesses particulares em motivação principal de sua existência, efetivando assim as condições concretas para a consolidação do individualismo na sua vida e na sociedade.

Historicamente, alguns grupos sociais foram e ainda são perseguidos por grupos que dominam as relações sociais. E, por mais que o discurso neoliberal apregoe que as condições de vida da população social estão melhores, o mesmo não é verossímil. Hespanha (2002) defende a tese de que na contemporaneidade, as sociedades capitalistas por meio da globalização, não fizeram outra coisa senão produzir o aumento da desigualdade social, além da gradual ausência de solidariedade social. $\mathrm{O}$ autor ilustra haver um efeito de segmentação social, mais intenso, consistindo na "descolagem" dos segmentos mais oprimidos, dos grupos sociais situados na base da sociedade e na ascensão dos(as) mais fortes, situados(as) no topo da pirâmide social.

A participante Rosiane apontou que diante das dificuldades também recorria aos familiares e amigos(as), pois sempre estavam unidos(as). Ela apresentou uma série de fotografias com seus familiares (lado materno e paterno), tendo em vista que tinha uma ótima relação com todos e contato constante com os mesmos. Disse que sua família era unida, fato confirmado durante as filmagens, ao evidenciar, ainda, que os familiares, além do afeto, sempre se faziam presentes em sua vida.

Sobre o contato com os familiares, Rosiane enfatizou que isso sempre acontecia aos finais de semana e que havia uma relação de cumplicidade muito forte entre eles, por meio dos momentos de descontração e carinho. Em um dos momentos de interação com seus familiares, todos participavam de um churrasco organizado pelo tio. Ao ser questionada sobre os motivos que impediam muitas vezes que outras famílias pudessem se reunir frequentemente, ela apresentou argumentos de que as questões financeiras são impeditivas de tal, todavia de maneira reducionista. Para ela, se as pessoas soubessem dividir melhor seu dinheiro, poderiam ter momentos de interação. Em nenhum momento, Rosiane apresentou clareza da lógica de exploração à qual milhares de trabalhadores(as) são submetidos(as) diariamente dentro do sistema capitalista, sendo que o montante financeiro recebido no fim do mês, muitas vezes, não contempla as necessidades básicas das famílias. Isso para os(as) que têm um posto de trabalho.

Rosiane valorizava muito as amizades que tinha, tendo em vista que eles(as) sabiam de seus gostos e contava tudo o que acontecia consigo a eles(elas). Mencionou diante da exibição de um trecho da filmagem, no qual estava interagindo com seus(suas) amigos(as), 
durante o período da noite, na rua, que era algo que fazia todos os dias. A maioria das amizades foi construída para além dos muros da escola, no bairro longínquo onde residia.

A participante Renata apresentou uma história de vida um tanto impactante, diante do histórico que a levou a ser adotada por um casal de tios que viviam em situação de pobreza. Conforme suas palavras:

Meu pai morreu e minha mãe não tinha condições de cuidar de mim. Então, eu teria que morar com uma família adotiva, foi perguntado para todos os parentes, mas nenhum deles quis ficar comigo. Então, eles foram os únicos que sobraram por parte do meu tio que mora com ela, então só sobraram eles para poderem me criar e com sete anos eu fui para lá (RENATA, PARTICIPANTE DA PESQUISA DE CAMPO).

Ao tirar uma foto da fachada da casa, fez referência a algo bom que aconteceu em sua vida, por ser o local onde foi morar depois de sua adoção, após viver um curto período de tempo em um abrigo de crianças e adolescentes numa cidade de médio porte do interior do estado de São Paulo. Na foto tirada da irmã sanguínea, por parte de mãe, apontou que a amava muito e que a mesma era o "anjinho espoleta" da casa; relatou que ela teve uma vida mais sofrida que a sua, pelo fato de não ter tido a oportunidade de conhecer seu pai. Renata mencionou que a irmã considerava os tios que a adotaram como se fossem os seus pais, diferente dela, que os via apenas como tios.

Assim, quando era criancinha, ela morava junto com a minha mãe. Mas, minha mãe não cuidava muito dela e teve um dia que, ela era bem pequenininha, tinha meses ainda, ela estava andando no quintal da casa e um tanque de cimento caiu em cima dela, daí ela ficou enfaixada da cabeça aos pés, por isso que eu falo que ela é espoleta. Ela quebrou a bacia, o fêmur, as duas pernas [...] quebrou tudo. Nisso o juiz a tomou da minha mãe e a levou para o LAR (abrigo). Nisso, minha tia tomou a iniciativa e viu que eu queria ter a minha irmã perto de mim e a adotou. Só que chegando em casa, a espoleta quebrou o braço. Então, assim, o mesmo tanto que eu sofri ela sofreu também, só que o pai dela não a assumiu; para ela o pai e a mãe dela são os pais adotivos. Agora eu não, como cheguei em casa com sete anos, a minha consideração é como tio e tia e não como pai e mãe, já ela os vê como pai e mãe, como se tivesse nascido da minha tia (RENATA, PARTICIPANTE DA PESQUISA DE CAMPO).

Chamou atenção o quanto a mesma mencionou a importância do sentimento amor, ao apresentar a foto de um bebê recém-nascido, da filha da tia que a adotou e que morava nos fundos de sua casa: 
É uma criança que todos nós estávamos esperando em casa. Ela é uma criança muito amada, [...] muito amada mesmo (RENATA, PARTICIPANTE DA PESQUISA DE CAMPO).

Ela apontou não ter muitas amizades na escola, pois se considerava uma garota fechada, sendo que tinha apenas duas amigas que residiam em seu bairro. Uma das amigas estava em sua classe (foram separadas na montagem de turmas para o Ensino Médio). Em sua fala ficou nítido o reflexo das constantes perseguições que sofria por parte dos(as) colegas de classe e escola. Todavia, disse não saber os motivos que geravam tal situação. No decorrer da pesquisa, constatou-se que na turma na qual estudava, havia estudantes com melhores condições econômicas que a sua; fato que parece ter implicações no processo de não aceitação de sua pessoa, aliado ao aspecto de ser fechada.

Ah eu não sou de fazer muita amizade, eu não converso muito, sou bastante fechada e assim em termos de qualidade de fazer amizade fácil, eu não consigo, sou bastante fechada, tenho poucos colegas. Aqui é raro (RENATA, PARTICIPANTE DA PESQUISA DE CAMPO).

Ao falar sobre as duas amigas ressaltou que tinha muito afeto e carinho por elas. Comentou, ainda, que as amigas eram muito carinhosas e que gostava muito delas. Nos momentos de dificuldades contava com a ajuda delas e do namorado. Ao fazer referência à necessidade das pessoas terem amizades, pontuou que antigamente não tinha e que vivia isolada e que as pessoas deveriam procurar construir amizades, para que possam ter alguém com quem se abrir e dialogar, em especial, nos momentos de necessidades.

[...] antigamente, por exemplo, se eu fosse sair para algum lugar eu não tinha amigos para ir junto, não tinha amigos para conversar, divertir e aprontar. A gente sai e faz de tudo [...] é muito bom você ter uma pessoa para se abrir e contar seus problemas, principalmente para um amigo. Porque nenhuma pessoa consegue ficar sozinha, deve sempre haver alguém para se conversar e se abrir (RENATA, PARTICIPANTE DA PESQUISA DE CAMPO).

Ficou evidente na vida dos(as) seis participantes o quanto suas famílias e amizades funcionavam como redes mediadoras de apoio e proteção, todos(as) apresentavam boa relação familiar. Embora as amizades não fossem quantitativamente elevadas, percebe-se a qualidade dessas relações. É condição essencial da sociabilidade humana o contato com o outro.

Torna-se imperioso ressaltar que esses processos de sociabilidade os conduziam à formação de suas personalidades, tendo em vista que as redes mediadoras de proteção são 
também expressões das condições e contradições postas pelas circunstâncias objetivas de vida. Por se constituírem no sistema capitalista são permeadas, também, por processos de alienação, que nem sempre dão conta da totalidade dos motivos e ações presentes na atividade humana. Assim, contraditoriamente, por mais que cumpram papel essencial, conforme os relatos das vítimas de bullying escolar, participantes desta pesquisa, ao auxiliá-los(as) frente o enfrentamento da condição que se encontravam, por meio dos processos de "resiliência em-si", não há como desconsiderar que os(as) participantes continuavam adaptados(as) à realidade social.

Apesar disso, não há como negar, a partir de Leontiev (1983) e Vigotski (2001), a necessidade e importância das relações sociais, no processo de desenvolvimento do humano. Seja diante da menor ou maior dificuldade, do que uma criança ou adolescente possa fazer sozinho(a) ou em colaboração, com a ajuda de alguém, tais aspectos reforçam a dinâmica do desenvolvimento e coincidem plenamente com o conceito de zona de desenvolvimento próximo (VIGOTSKI, 1995).

Entretanto, conforme Hespanha (2002), a atualidade por meio das ideologias dominantes, em especial, nos países mais ricos, reforça o processo de individualização, na busca em se ter cada vez mais uma "vida própria". As pessoas são levadas a aceitar, a acreditar e agirem como se fossem as responsáveis por todos os seus próprios problemas. Dessa forma, apresentam-se alguns elementos do conceito de gênero humano, a partir do qual Duarte (1999) reafirma que os resultados decorrentes do processo de humanização histórico-social não são cumulativos e sequer são transmitidos pela herança genética. A formação do indivíduo é tida como parte do processo histórico de objetivação do gênero humano, no qual há uma relação imbricada entre a singularidade social do indivíduo junto ao gênero humano.

Não se pode perder de vista que na perspectiva da teoria histórico-cultural, os elementos sociais vão constituir a individualidade de cada ser humano e revelarão assim, a personalidade de cada indivíduo. Contudo, o indivíduo nunca se relaciona imediatamente com o gênero humano, havendo uma relação mediatizada, por parte do indivíduo, diante das circunstâncias históricas, sociais e culturais na realidade em que o mesmo se encontra inserido (DUARTE, 1999; LEONTIEV, 1983).

Perante tais esclarecimentos, a educação escolar, por meio de um trabalho educativo revolucionário, pode ser um espaço de apoio e proteção aos(as) estudantes, mediante as imposições ideológicas do capitalismo, que se fazem presentes nos mais 
variados espaços de socialização humana. A escola deve ser entendida como um espaço intencional, que ao utilizar-se do conhecimento científico e ao desenvolver o trabalho educativo pode auxiliá-los(as) a desenvolverem uma maior consciência da realidade, para que se possa superar o processo formativo em-si e auxiliar no processo de construção da individualidade para-si dos sujeitos. A educação escolar pode possibilitar que a sua "comunidade" como um todo, mantenha uma relação consciente com o gênero humano e se emancipe frente às dificuldades geradas pela sociedade capitalista.

De acordo com Oliveira (1996, p.19), os entraves para que tal processo se efetive estão assentados na alienação que perpassa as relações sociais de produção. Porém, "é preciso compreender como essa forma contraditória de desenvolvimento do gênero humano gera, ao mesmo tempo em que a reprodução dessas relações de alienação e exploração do homem pelo homem, as próprias condições de sua superação". Ou seja, a educação escolar pode auxiliar os(as) seus(suas) agentes a buscarem o conhecimento dessas possibilidades, a fim de que eles se percebam como "indivíduos transformadores", ainda que dentro das relações sociais alienadas.

Ao pensar a escola como escola-comunidade Viotto Filho (2005) afirma que é importante valorizar a relação indivíduo-comunidade e superar a relação indivíduo-grupo, pois, conforme Heller $(1977,2000)$ a relação indivíduo-grupo é permeada por circunstâncias imediatas. A relação indivíduo-comunidade mais significativa ocorre à medida que os sujeitos se envolvam por inteiro nas relações, ou seja, a individualidade encontra-se presente nas relações e possibilitam a construção do grupo, o qual se converte, paulatinamente, em comunidade, sendo que cada sujeito tem a oportunidade de resgatar a totalidade da sua individualidade (HELLER, 1977).

Esclarece a autora que "nem todo grupo, portanto, pode ser considerado como uma comunidade, embora qualquer grupo possa chegar a ser comunidade [...]" (HELLER, 2000, p.66). A partir disso é possível pensar na escola atual e no quanto ela poderá vir-aser uma escola-comunidade, pensada e organizada pelos próprios sujeitos dela participantes; uma organização que supere, pela ação coletiva, livre e democrática, a instituição escolar tradicional, que se configura eminentemente pela existência de meros grupos circunstanciais.

\section{A escola como um local de apoio e proteção}


Prosseguindo, aborda-se o papel da escola como um espaço de proteção na vida dos(as) adolescentes expostos(as) ao bullying escolar e apresentam-se alguns exemplos de práticas que podem favorecer a mediação do conhecimento científico-humano e a emancipação dos(as) mesmos(as), num projeto revolucionário que os(as) auxilie na busca pela transformação social, bem como no pleno desenvolvimento de suas personalidades. Em contrapartida, serão visibilizados alguns exemplos de práticas que distanciam a escola de sua função social mais ampla, ou seja, a socialização do conhecimento humano. Num primeiro momento far-se-á a descrição das práticas e elementos que os(as) participantes da pesquisa destacaram como importantes em sua trajetória escolar e, posteriormente, na perspectiva da teoria histórico-cultural, serão apresentados os elementos que dificultam o processo de humanização e o pleno desenvolvimento da personalidade humana, os quais evidenciam o quanto as escolas por meio de modelos autoritários, pouco ou nada auxiliam na formação da generecidade para-si.

Achilles mencionou que sua escola era boa e que havia professores que funcionavam como "pais", ao sempre explicarem os conteúdos presentes no processo de ensino-aprendizagem, de forma articulada com situações concretas e objetivas da vida.

Em uma das fotos, na qual o jovem apareceria ao lado de várias pessoas, ele disse que a mesma simbolizava uma aula diferenciada de Física que teve na escola, com os(as) estagiários(as) da referida área. Destacou que gostava muito de Física, tendo em vista que o professor explicava bem. Achilles era um garoto que contestava muito os(as) professores(as) com posturas autoritárias, por isso ele sempre estava sendo "marcado" por alguns(algumas) docentes. Entretanto, ele ponderou que o problema não residia no fato do professor "pegar no pé" do estudante para que o mesmo aprendesse, mas antes disso o docente teria que oferecer boas aulas. Como exemplo, mencionou as aulas da professora de Matemática:

Dentro da escola ela é a professora que mais se impõe e que ensina Matemática. Pega no pé heim! Não faz a lição para você ver, daí ela fala e fala. Isso que é bom. Tem professor que ensina e tem professor que acha que ensina, mas a gente acha que não (ACHILLES, PARTICIPANTE DA PESQUISA DE CAMPO).

Esse comentário evidencia a importância que o estudante confere aos profissionais que medeiam o conhecimento humano e que mostram o seu papel social perante aos estudantes, ao terem clareza sobre a função do seu componente curricular, além de apresentarem aulas planejadas. Todavia, o mesmo fez um contraponto com uma situação 
em que foi suspenso, ao mostrar um lado que, muitas vezes, se faz recorrente nas escolas, ou seja, as medidas autoritárias, através das quais professores e gestores tentam se "impor" perante aqueles que não se ajustam ao perfil de estudante "ideal". Muitos(as) professores(as) têm a crença que os(as) estudantes ideais não conversam, não se movimentam, não questionam e sempre concordam com tudo o que for dito, bem como que os(as) bons(boas) diretores(as) são aqueles(as) que em qualquer circunstância apoiam os(as) professores(as). Tal aspecto também se fez presente na fala de Achilles.

A professora não deu o visto, eu fiz o trabalho de Biologia um dia antes. Estava no finalzinho da aula, daí fui levar o trabalho para ela vistar, nisso ela disse que na próxima aula faria isso. Beleza, quando cheguei à aula seguinte, levei para ela vistar. Não! Mas, professora, a senhora disse que iria dar meu visto. Eu não vou te dar o visto. Falei, tudo bem. Chegou ao fim da aula, fiz a lição e faltava um minuto. Toma professora está aqui. O quê? Para você dar o visto. Não vou vistar mais. Por quê?? Ah porque acabou. Ah mas tem um monte de pessoas acabando, sabe a senhora que "se foda", não preciso disso. Ai ela retrucou, vai "foder" você, vou falar com a diretora para chamar sua mãe. Quando cheguei para falar com a diretora ela chegou do meu lado, quero a mãe desse aluno. Ah diretora, mas e o que ela fez? E você é santo? Olhou para mim. Nossa é sempre assim cara, diretor só vai favorecer professor. É a professora está certa, vou chamar sua mãe. Virei e falei, essa escola é um inferno. Se é um inferno você não precisa vir amanhã porque estará de suspensão. E me deu a suspensão (ACHILLES, PARTICIPANTE DA PESQUISA DE CAMPO).

Ele apontou, ainda, que os(as) professores(as) e gestores(as) com posturas autoritárias sempre serão perseguidos pelos(as) estudantes, pelo fato dos mesmos não os respeitarem, citou como exemplo, o caso de um grupo de estudantes que pegaram os extintores da escola e o usaram para manchar o carro de uma gestora. Tais ocorrências, segundo Achilles, foram desencadeadas por causa de uma "regra" que proibia o uso dos bonés. Embora ele se diga contrário às medidas dos(as) colegas de escola, sua indignação refere-se ao que vem sendo discutido por pesquisadores(as) da área da Educação, ou seja, o fato das escolas se preocuparem em ficar criando regras que pouco ou nada contribuem com o seu verdadeiro papel, ou seja, o de trabalhar com o conhecimento humano produzido historicamente e que vem sendo apropriado por poucos(as) (ASBAHR, 2011; DUARTE, 2015; FACCI; TULESKI; BARROCO, 2009).

Destaca-se a partir fala de Achilles, a importância da escola como mediadora do conhecimento humano na visão da Pedagogia Histórico-Crítica (DUARTE, 2015; SAVIANI; DUARTE, 2012) ou da Escola-Comunidade (VIOTTO FILHO, 2005). Como 
defendido, entende-se que a educação escolar seja um importante espaço para que os(as) estudantes adquiram consciência das relações que medeiam suas vidas, a fim de que lutem pela transformação das relações sociais, bem como que alcancem o desenvolvimento livre e universal de suas personalidades. Somente assim, eles poderão superar os processos decorrentes da "resiliência em-si", que marcam as possibilidades de um enfrentamento limitado das adversidades, mediante o fato de que os indivíduos continuam inseridos nas relações capitalistas de produção.

De acordo com Taffarel (2016), o conhecimento deve ser tratado desde sua gênese, ao contemplar a sua historicidade. Tais aspectos visam favorecer que os(as) estudantes compreendam seu papel como sujeitos históricos e que sejam capazes de interferirem nas atividades sociais organizadas em uma sociedade que nunca foi estática e almejarem a superação das relações sociais, a fim de alcançarem o pleno desenvolvimento da personalidade humana.

A ação pedagógica, num processo revolucionário, por meio do conhecimento científico sistematizado deve objetivar a formação de indivíduos autônomos e conscientes sobre o seu papel frente ao modelo que se vive, e que também exerce influências sobre as diferentes manifestações humanas presentes ao seu redor. Isso se aplica a todas as áreas do conhecimento humano.

Leontiev (1983) e Martins (2011) elucidam que a consciência é o conhecimento compartilhado, no sentido de que a consciência individual só poderá ser desenvolvida se houver uma consciência da realidade social mediante o entendimento de que ela é resultado das relações e mediações produzidas ao longo do desenvolvimento da humanidade.

Ao refletir sobre sua escola, por meio das fotografias e filmagens a participante Rosiane mencionou que ela era muito boa, tendo em vista que alguns(algumas) professores(as) sempre explicavam os assuntos que ela tem dificuldades. Todavia, ao mencionar sobre a importância da escola, a mesma caiu nas armadilhas da lógica do sistema capitalista ao defender que as pessoas tinham que estudar para trabalhar e ganhar dinheiro, como se a grande função social da escola fosse a de preparar as pessoas para o mercado de trabalho.

Asbahr (2011), Bruno (2011) e Martins (2011) constataram que a educação, a serviço da burguesia e da manutenção das relações sociais é reforçada, justamente, por meio de discursos, como por exemplo, que relacionam a educação ao mercado de trabalho. Postula-se na perspectiva do capital que a escola deve oferecer conhecimentos necessários 
para que os(as) jovens adentrem ao mercado de trabalho com qualificação necessária, para que o crescimento econômico das nações ocorra normalmente.

Ao comentar sobre uma situação em que necessitou do apoio da direção frente às perseguições de bullying escolar que estava sofrendo, Rosiane destacou que o pessoal da direção não agiu adequadamente. Tal aspecto evidencia conforme o que ela disse, que nem sempre as decisões tomadas são as melhores. É importante deixar claro que este artigo não tem nenhuma intenção de produzir críticas aos(as) gestores(as) das escolas de nosso país, até mesmo porque, na maioria dos casos, suas ações e condutas são reflexo do modelo de formação que tiveram, além das condições objetivas de trabalho, o que não os favorece a realizar uma intervenção consciente e balizada a partir de uma concepção transformadora de mundo e educação. Aliado a isso, muitas vezes, são chamados(as) a tomar decisões imediatas ou as tomam tentando apenas resolver os problemas momentaneamente.

O menino havia começado me chamar de vareta de pau, disso e daquilo. Daí eu fui até a direção e falei com a diretora, nisso ela pediu para que ele subisse. Quando ele chegou lá ela falou, ou vocês pedem desculpas um para o outro ou os dois vão ficar de suspensão. Ou seja, a culpa caiu em mim e não nele. Nisso eu me senti muito mal, fui lá para não resolver nada (ROSIANE, PARTICIPANTE DA PESQUISA DE CAMPO).

Esse é mais um exemplo de intervenção que não atua na raiz do problema, ao passo que o bullying escolar continuará sendo reproduzido na dinâmica escolar. Os(as) estudantes por sua vez, continuarão centrados(as) no modelo de relações sociais que produzem o fenômeno, com a impressão de que as coisas são assim, e que pouco há o que se fazer. Há apenas um enfrentamento momentâneo. No atual modelo de escola, as práticas de violência, ao serem influenciadas pelas relações objetivas, trazem à tona, a necessidade de se buscar a transformação das relações sociais (FRANCISCO; COIMBRA, 2015).

Assim como Rosiane, Elenita, em um dos momentos da filmagem, ao estar realizando uma tarefa escolar em sua casa na companhia de uma amiga, questionou a utilidade de uma disciplina do currículo escolar (Física), ao mencionar que ela não tinha utilidade em sua vida. Tais tarefas, inclusive, estavam sendo feitas por meio da cópia das resoluções dos exercícios, por meio de um site que oferecia o gabarito. Em contrapartida, mencionou que gostava das aulas de Química, pois o professor realizava experimentos e deixava a aula mais atrativa.

As intervenções como as produzidas na aula de Química são importantes, mas apenas isso, ainda, não é suficiente, uma vez que a educação escolar precisa criar 
condições de apropriação dos conhecimentos humano-genéricos tais como a ciência, a filosofia, as artes, a cultura corporal, as letras, a política, a ética dentre outros conhecimentos essenciais ao processo de humanização dos indivíduos (DUARTE, 1999, 2015).

Irineu também destacou gostar da escola que estudava. Numa sequência de quatro fotos apresentou uma professora que ele sempre admirou pela sua postura frente ao componente curricular de Ciências; uma da diretora da escola, na tentativa de mostrar a necessidade dos alunos se aproximarem da direção e professores; uma foto da professora de Língua Portuguesa que simbolizava o quanto a aprendizagem e o conhecimento influenciavam no futuro de um indivíduo e uma foto de um professor substituto, ao referenciar o seu comprometimento com o processo de ensino-aprendizagem. Em suas palavras, Irineu defendia o papel da educação para os(as) mais jovens poderem crescer e desenvolver melhor. Todavia, destacou que poucos(as) eram os(as) professores(as) que cumpriam essa função nas escolas.

Eu tenho minha opinião própria, por mais que eu não tenha muita noção do que acontece eu sempre procuro me inteirar e estar perguntando para estar a par das coisas que acontecem. Mas eu também tenho minha opinião e não me deixo ser enganado como a maioria da população, que é enganada e acha que está por cima ainda [...] Por meio da escola, as professoras alertam bastante. É importante fazerem isso nas escolas, ou seja, se alertar sobre política, porque é um assunto pouco falado. É importantíssimo os professores estarem falando, não do ponto de vista do governo, mas do ponto de vista da população (IRINEU, PARTICIPANTE DA PESQUISA DE CAMPO).

Ele pontuou sobre as práticas que considerava importantes, as quais favoreciam os(as) estudantes a adquirirem mais criticidade, bem como as contrárias a esse processo.

Olha as que fazem debates, pois é uma coisa que ajuda o aluno a ficar mais crítico, e que ajuda o aluno pensar mais além [...] E os negativos são aqueles professores que chegam desinteressados; atrasados; que faltam; que exigem, mas não cumprem; que tratam os alunos com falta de educação (IRINEU, PARTICIPANTE DA PESQUISA DE CAMPO).

O estudante apresenta um posicionamento crítico ao conferir importância à educação, em especial, por meio da intervenção docente frente aos interesses das camadas populares da população. De acordo com Martins (2011), não se pode perder de vista a natureza concreta do homem, bem como a natureza concreta da educação, caso contrário, as intervenções estarão limitadas a função de instruir e adaptar os indivíduos a resolver 
apenas as necessidades cotidianas. A natureza histórico-social do homem apresenta a educação, com vistas à humanização, por meio do desenvolvimento da práxis. A educação, indissociavelmente deve buscar a transformação do indivíduo e da sociedade. A tarefa educativa pressupõe um projeto pedagógico atrelado a um projeto político, pois ambos são concernentes a uma práxis transformadora.

Andréia disse gostar da escola que estudava e da cidade que residia, porque considerava a educação do município boa. A escola teve um papel fundamental em sua vida ao estimular o gosto pela literatura, hábito que cultivava e que foi decisivo, para que ela ansiasse cursar a faculdade de Letras. Aliado a isso, a participante ressaltou o papel de uma docente que "mudou a cara" da disciplina de Língua Portuguesa ao estimular as práticas destacadas anteriormente. Renata também apontou gostar da escola que estudava, disse que a instituição tinha professores e funcionários comprometidos com as funções desempenhadas.

Sobre os posicionamentos dos(as) estudantes, mediante as práticas aqui apresentadas, salienta-se a partir de Silva, Silva e Martins (2006), a educação escolar institucionalizada, no sistema capitalista possui determinações classistas desde a sua constituição. Entretanto, a mesma fornece também elementos para que se possa vislumbrar a superação dessa condição que se encontra.

Para Martins (2004), os processos de tomada de consciência dos motivos presentes nas atividades, por meio de conceitos, conduzem ao controle exercido pela consciência sobre tais atividades, de tal modo que colocam os indivíduos em relação com suas condições objetivas de vida. Ao refletir a partir dos conceitos e significados que vão se apropriando, podem objetivá-los para além de sua existência individual, inclusive na luta pela superação do atual modelo social.

Tais aspectos foram analisados a partir do estágio atual de desenvolvimento que se encontravam os(as) participantes da pesquisa, ao passo que por construírem suas personalidades a partir do contato com as condições objetivas de vida, eles(elas), se encontravam impedidos de se posicionarem efetivamente frente ao bullying escolar experienciado, por meio da "resiliência em-si", frente a tal adversidade, até mesmo porque estavam condicionados a se adaptarem ao contexto social. Daí a importância da educação escolar articulada a um projeto político-pedagógico revolucionário, a fim de superar essa condição. 
Se houver intenção a se contrapor à concepção burguesa de educação, por meio de uma concepção histórico-cultural de educação, os(as) agentes escolares, bem como a sociedade devem iniciar por meio de sua negação (SAVIANI, 2008). A classe dominante não tem interesse na transformação histórica da escola pública. A mobilização deve partir no seio da classe trabalhadora, seja por meio dos movimentos sociais, das associações e grupos para se estudar e partilhar os conhecimentos adquiridos nas diferentes esferas de atuação, ou seja, nas escolas, universidades e empresas, a fim de não se deixar morrer a utopia da transformação social, que poderá auxiliar os indivíduos no pleno desenvolvimento de suas personalidades.

\section{SÍNTESE}

$\mathrm{Na}$ perspectiva da teoria histórico-cultural, que tem como base epistemológica o materialismo histórico dialético, os objetos de estudo aqui analisados (bullying escolar e os processos de "resiliência em-si"), foram entendidos para além de suas conceituações numa perspectiva neoliberal. É condição sine qua non estudar tais conceitos em articulação com a estrutura social mais ampla, a fim de se romper com o modo dominante de pensar, caso contrário, continuarão sendo fenômenos idealistas e abstratos.

Em nenhum momento o bullying escolar foi entendido como responsabilidade exclusiva de um indivíduo singular. Os(as) participantes desta pesquisa foram perseguidos(as) em função de não se adequarem aos estereótipos corporais ditados pela mídia e meios de comunicação, por serem pobres, por serem excessivamente aplicados(as) nas atividades escolares e por adotarem determinadas crenças religiosas.

Os dados deste artigo revelaram a importância que as redes mediadoras de apoio e proteção, sobretudo aquelas expressas nas relações interpessoais e familiares tiveram na vida dos(as) participantes da pesquisa, ao funcionarem como um ponto de apoio ou referências frente às adversidades vivenciadas, inclusive, aquelas promotoras de bullying escolar. Há que se destacar que muitas das práticas e atividades sociais que os(as) mesmos(as) participavam, também funcionaram como mecanismos mediadores de proteção em suas vidas, ao passo que eles(elas) puderam se sentir valorizados(as) e reconhecidos(as) perante o coletivo.

Há que se ressaltar que as redes mediadoras de proteção são também expressões das condições e contradições postas pelas circunstâncias objetivas de vida. Por se constituírem no sistema capitalista são permeadas, também, por processos de alienação, que nem 
sempre dão conta da totalidade dos motivos e ações presentes na atividade humana. Contraditoriamente, por mais que cumpram papel essencial, conforme os relatos das vítimas de bullying escolar, participantes desta pesquisa, ao auxiliá-los(as) frente o enfrentamento da condição que se encontravam, por meio dos processos de "resiliência em-si”, não há como desconsiderar que os(as) participantes continuam adaptados(as) à realidade social.

Por fim, destaca-se o papel que a escola pode desempenhar em seu processo de formação, por meio do desenvolvimento de suas funções psicológicas superiores, atreladas à formação de personalidades com consciência social e política. Consequentemente almeja-se que ela prepare os indivíduos para superar os antagonismos gerados a partir das relações sociais presentes no capitalismo, na luta por outra estrutura social, onde prevaleça à unidade entre atividade e motivos vitais.

\section{Referências bibliográficas}

ALMEIDA, A. A.; CAURCEL, M. J. Scan-bullying. Universidade do Minho: Braga, 2005.

AVILÉS, J. M. Éxito escolar y ciberbullying. Boletín de Psicología, Valencia-ES, n.98, p.73-85, mar. 2010.

ASBAHR, F. S. F. Por que aprender isso professora? Sentido pessoal e atividade de estudo na Psicologia Histórico-Cultural. 2011. 220f. Tese (Doutorado em Psicologia Escolar e do Desenvolvimento humano) - Instituto de Psicologia, Universidade de São Paulo, São Paulo.

BANDEIRA, C. M. Bullying: auto-estima e diferenças de gênero. 2009. 69f. Dissertação (Mestrado em Psicologia). Instituto de Psicologia, Universidade Federal do Rio Grande do Sul, Porto Alegre.

BOTTEL, M. L.; BERMÚDEZ, M. R. Bullying: aspectos históricos, culturales y sus consecuencias para la salud. Revista Cubana de Medicina General Integral, La Habana, v. 33, n. 1, p. 154-162, jan./mar. 2017. Disponível em: <http://scielo.sld.cu/pdf/mgi/v33n1/mgi14117.pdf>. Acesso em: 27 nov. 2018.

BRUNO, L. Educação e desenvolvimento econômico no Brasil. Revista Brasileira de Educação, Rio de Janeiro, v.16, n.48, p.545-562, set./dez. 2011.

DUARTE, N. A individualidade para-si: contribuição a uma teoria histórico-social da formação do indivíduo. 2. ed. Campinas: Autores Associados, 1999.

DUARTE, N. Educação escolar, teoria do cotidiano e a escola de Vigotski. 4. ed. Campinas: Autores Associados, 2007. 
DUARTE, N. A importância da concepção de mundo para a educação escolar: porque a pedagogia histórico-crítica não endossa o silêncio de Wittgenstein. Germinal: Marxismo e Educação em Debate, Salvador, v. 7, n. 1, p. 8-25, jun. 2015.

EDWARDS, A.; APOSTOLOV, A. A cultural-historical interpretation of resilience: the implications for practice. Critical Social Studies, Basingstoke-UK, v.09, n.01, p.70-84, jan./jun. 2007.

FACCI, M. G. D.; TULESKI, S. C.; BARROCO, S. M. S. Escola de Vigotski: contribuições para a Psicologia e a Educação. Maringá: Eduem, 2009.

FRANCISCO, M. V.; COIMBRA, R. M. Análise do bullying escolar sob o enfoque da psicologia histórico-cultural. Estudos de Psicologia, Natal, v. 20, n. 3, p. 184-195, jul./set. 2015.

GANDRA, L. M. M.; VIOTTO FILHO, I. A. T.; PONCE, R. F. A criança e seu processo de desenvolvimento na atualidade: uma visão histórico-cultural. In: VIOTTO FILHO, Irineu Aliprando Tuim; PONCE, Rosiane de Fátima (Orgs.). Psicologia \& Educação: perspectivas críticas para a ação psicopedagógica. Birigui: Boreal Editora, 2012.

GILLEN, J. et al. A Day in the Life: advancing a methodology for the cultural study of development and learning in early childhood. Early Child Development and Care, London-UK, v.177, n.2, p.207-218. 2006.

HELLER, A. Sociologia de la vida cotidiana. Barcelona: Península, 1977.

HELLER, A. O cotidiano e a história. 8ª ed. São Paulo: Paz e Terra, 2000.

HESPANHA, P. Individualização, fragmentação e risco social nas sociedades globalizadas. Revista Crítica de Ciências Sociais, Coimbra-PT, n.63, p.21-31, out. 2002.

LEONTIEV, A. N. O desenvolvimento do psiquismo. Lisboa: Livros Horizonte, 1978.

LEONTIEV, A. N. Actividad, conciencia, personalidad. 2. ed. La Habana: Editorial Pueblo y Educación, 1983.

LEONTIEV, A. N. Uma contribuição à teoria do desenvolvimento da psique infantil. In: VIGOTSKI, Lev Seminovich; LURIA, Alexander Romanovich; LEONTIEV, Alexis Nikolaevich. Linguagem, desenvolvimento e aprendizagem. 2. ed. São Paulo: Ícone, 1989.

LIBÓRIO, R. M. C. Construindo resiliência através da participação em práticas culturais: a articulação entre os indivíduos e processos inter-relacionais e comunitários na facilitação do protagonismo. Relatório de pesquisa - FAPESP, 2011. (não publicado).

LISBOA, C.; BRAGA, L. L.; EBERT, G. O fenômeno bullying ou vitimização entre pares na atualidade: definições, formas de manifestação e possibilidades de intervenção. Contextos Clínicos, São Leopoldo, v. 2, n.1, p. 59-71, jan./jun. 2009. 
MARTINS, L. M. Análise sócio-histórica do processo de personalização de professores. 2001. 194f. Tese (Doutorado em Educação) - Faculdade de Filosofia e Ciências, Universidade Estadual Paulista, Marília.

MARTINS, L. M. A natureza histórico-social da personalidade. Caderno Cedes, Campinas, v.24, n.62, p.82-99, abr. 2004.

MARTINS, L. M. A formação social da personalidade do professor: um enfoque vigotskiano. Campinas: Autores Associados, 2011.

MARX, K.; ENGELS, F. A ideologia alemã. 11. ed. São Paulo: Martins Fontes, 1974.

OLIVEIRA, B. O trabalho educativo: reflexões sobre paradigmas e problemas do pensamento pedagógico brasileiro. Campinas: Autores Associados. 1996.

PAULO NETTO, J. Introdução ao estudo do método de Marx. São Paulo: Expressão Popular, 2011.

OLWEUS, D. Conductas de acoso y amenaza entre escolares. 3. ed. Madrid: Ediciones Morata, 2006.

SAVIANI, D. Educação socialista, Pedagogia Histórico-Crítica e os desafios da sociedade de classes. In: LOMBARDI, J. C.; SAVIANI, D. Marxismo e educação: debates contemporâneos. 2.ed. Campinas: Autores Associados; HISTEDBR, 2008, p. 223-274.

SAVIANI, D.; DUARTE, N. Pedagogia histórico-crítica e lutas de classes na educação escolar. Campinas: Autores Associados, 2012.

SILVA, C. R.; SILVA, L. F.; MARTINS, S. T. F. Marx, ciência e educação: a práxis transformadora como mediação para a produção do conhecimento. In: I EBEM - Encontro Brasileiro de Educação e Marxismo, v.1, n.1, 2006, Bauru. Anais... Bauru: UNESP, 2006, p.7-18.

TAFFAREL, C. N. Z. Pedagogia histórico-crítica e metodologia de ensino criticosuperadora da educação física: nexos e determinações. Nuances: estudos sobre educação, Presidente Prudente, v. 27, n. 1, p. 05-23, jan./abr. 2016.

UNGAR, M. The negotiating resilience project: protective processes of children in transtition across cultures and contexts. Manual de Pesquisa não publicado. 2008.

UNGAR, M.; BROWN, M.; LIEBENBERG, L.; OTHMAN, R.; KWONG, W. M.; ARMSTRONG, M.; GILGUN, J. Unique Pathways to Resilience across Cultures. Adolescence, San Diego-USA, v.42, n.166, p.287-310, jun./ago. 2007.

UNGAR, M.; CLARK, S. E.; KWONG, W.; MAKHNACH, A.; CAMERON, C. A. Studying resilience across cultures. Journal of Ethnic and Cultural Diversity in Social Work, Philadelphia, PA-uSA, v.14, n.3/4, p.1-19, out./dez. 2005.

UNGAR, M.; LIEBENBERG, L. The child and youth resilience measure CYRM - user manual. International Resilience Project: Dalhousie University, Canada, 2008. 
VIOTTO FILHO, I. T. A. Psicologia Escolar e Psicologia Social-Comunitária: diálogos para a construção de uma perspectiva crítica de atuação do psicólogo na escola. 2005. 200f. Tese (Doutorado em Educação - Psicologia da Educação). Pontifícia Universidade Católica de São Paulo, São Paulo.

VYGOTSKY, L. S. Obras escogidas III: problemas del desarrollo de la psique. Madrid: Visor, 1995.

VYGOTSKY, L. S. Obras escogidas II: Problemas de Psicología General. 2.ed. Madrid: A. Machado Libros, 2001.

ZEQUINAO, M. A. et al. Bullying escolar: um fenômeno multifacetado. Educação e Pesquisa, São Paulo, v. 42, n.1, p.181-198, mar. 2016. Disponível em: http://dx.doi.org/10.1590/S1517-9702201603138354. Acesso em: 27 nov. 2018.

Recebido em: 31.07.2017 Aceito em: 30.11.2018 